\title{
Sprengel's deformity and unilateral absent kidney: A case report
}

\author{
Amit Sarkar ${ }^{1}$, Amitabha Bandyopadhyay ${ }^{2}$, Shovan Kumar Das ${ }^{3}$, Koushik Mondal ${ }^{4}$, Sanjai Kumar Singh ${ }^{5}$ \\ ${ }^{1}$ Residential Medical Officer Cum Clinical Tutor, ${ }^{2}$ Associate Professor, ${ }^{4}$ Postgraduate Trainee, ${ }^{5}$ Postgraduate Trainee, Burdwan Medical \\ College, Burdwan, West Bengal, India, ${ }^{3}$ Medical Officer (Physician), Sub-Divisional Hospital, Ghatal, West Midnapore, West Bengal, India
}

\section{A B S T R A C T}

The Sprengel's deformity is a congenital condition where the scapula on one or both sides are underdeveloped or abnormally high in position. An interesting rare case of Sprengel's deformity and unilateral absent kidney is being reported. The Sprengel's deformity should not be left undiagnosed.

Key words: Sprengel's deformity, Unilateral absent kidney

\section{INTRODUCTION}

The Sprengel's deformity is a rare, but most common congenital anomaly of the shoulder. ${ }^{1}$ The deformity is due to failure of descent of the scapula in intrauterine life resulting in underdeveloped and high placed scapula. The Sprengel's deformity is associated with cosmetic deformity and decreased shoulder function. ${ }^{2}$ Here, we report an interesting case of Sprengel's deformity with unilateral absent kidney.

\section{CASE REPORT}

A 30 years male attended outpatient department of our hospital with the chief complaints of left shoulder and chest pain intermittently and deformity of left shoulder since childhood. Family history was unremarkable for any congenital disorder.

On clinical examination, left shoulder was at higher level than right shoulder in standing position (Figure 1). His neck was apparently shorter than normal. There was restriction of active and passive rotation and lateral bending of neck. The active abduction of left shoulder was not possible beyond 90 degree angle. Examination of right shoulder was normal. On systemic examination, no abnormality was detected.

On investigation, routine complete blood count and blood biochemistry did not show any abnormality. X-ray of shoulder showed absent scapula on left side with presence of omovertebral bone (Figure 2). Ultrasonography and Computed Tomographic scan of abdomen showed absent left kidney (Figure 3). He was advised for conservative management with analgesic.

\section{DISCUSSION}

Eulenberg first described the deformity what later became known as Sprengel's deformity, as high-grade dislocation of the scapula in $1863 .^{3}$ Then after two decades, Willet

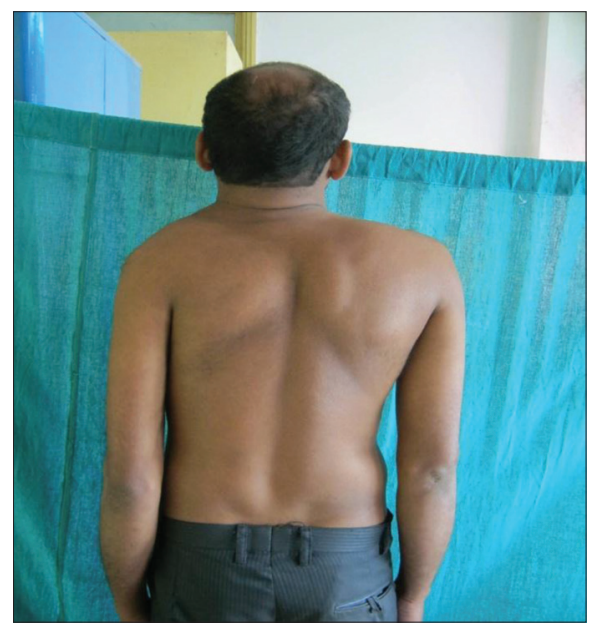

Figure 1: Sprengel's deformity of left shoulder. The left shoulder is elevated to higher level than right shoulder 


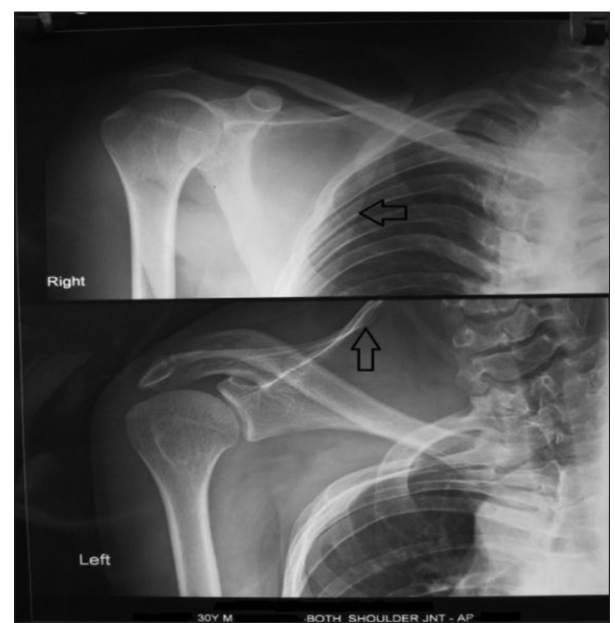

Figure 2: X-ray of right shoulder region showing scapula at normal position (arrow pointing towards left). The scapula is missing from normal position on the left side and omovertebral connection is seen (arrow pointing upwards)

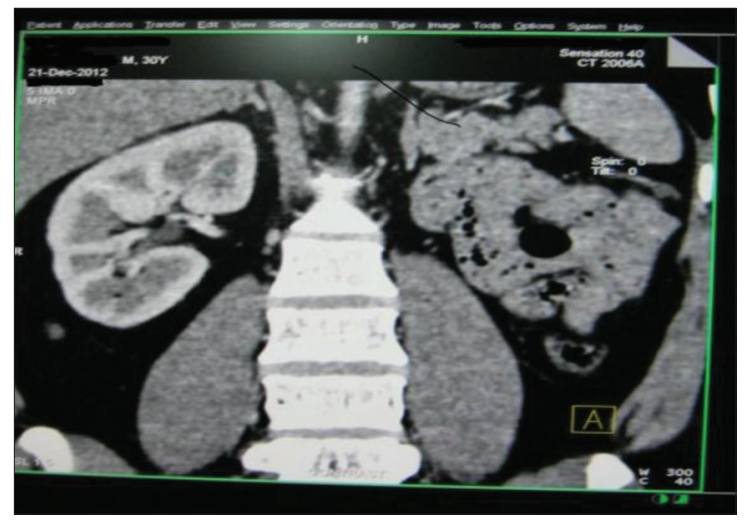

Figure 3: 3-D Computed Tomographic Scan showing absent kidney on left

and Walsham reported two cases of this clinical condition and were first to describe the omovertebral bone, as well as first to describe the excision of the bone, with good results. ${ }^{4}$ Sprengel described four cases of upward displacement of the scapula in $1891 .{ }^{5}$ Kolliker also described four cases in 1891 and named the condition Sprengel's deformity. ${ }^{6}$

The scapula is a cervical appendage that normally differentiates opposite mid cervical vertebral region at about 5 weeks of gestation. ${ }^{7}$ This structure normally descends to the thorax by the end of the third month of intrauterine life. The failure of this descent of the scapulae from $\mathrm{C} 5-\mathrm{T} 1$ position in the neck to T2-T7 position in posterior thorax during embryonic development results in Sprengel's deformity. Similar to our patient, the undescened scapula is usually hypoplastic and is located higher than normal in the neck or upper thoracic region. Because of the upwardly rotated superomedial angle of the scapula, the ipsilateral side of neck appear fuller. The passive movement of the shoulder joint may be normal. In $40 \%$ of patients with a Sprengel's deformity, active abduction is limited to less than 100 degree angle, which was also seen in our patients. The periscapular muscles may be fibrotic and contracted. An omovertebral connection, which may be fibrous, cartilaginous or bony may exist in about one third of cases. ${ }^{1,8}$ This connection is between the superomedial angle of the scapula to the spinous process, lamina or transverse process of the cervical vertebrae.This connection was seen in present case. Similar to our patient, the left side is usually more commonly affected than the right side. Females are affected three times more than the males, but our patient was male. The sprengel's deformity may be associated with other syndromes like Klippel-Feil syndrome, Greig syndrome, Poland syndrome etc. Additionally, costovertebral defects (spina bifida and kyphoscoliosis) ; maldevelopement of pectoral girdle bones (clavicle, humerus) and musculature (pectoralis major, trapezius) may be present. Congenital malformations that may be present with Sprengel's deformity are talipes eqino-varus, pes valgus, hallux valgus, shortening of femur, congenital dislocation of the hip, defects of hand or finger, bifid ear, cleft palate, high arched palate, strabismus, underdeveloped or supernumerary mammary gland, dextrocardia, absent or floating kidney, congenital inguinal hernia, inencephaly. The left kidney was absent in our patient.

Based on the severity of the condition, different gradings of Sprengel's deformity are as follows: ${ }^{10}$

Grade 1: The deformity is very mild. The deformity cannot be noticed with the clothes on.

Grade 2: The deformity is mild. The superomedial portion of the high scapula is visible as a lump.

Grade 3: The deformity is moderate. The affected shoulder is elevated $2-5 \mathrm{~cm}$ higher than the opposite shoulder.

Grade 4: The deformity is severe. The superomedial angle is at the occiput, with neck webbing.

Rickets, osteomalacia, malunited scapular fracture, paralysis, cervical tuberculosis are considered in the differential diagnosis of Sprengel's deformity.

Surgical intervention is required with significant cosmetic deformity and restriction of shoulder abduction in children between age of three to eight years. So, diagnosis should not be left until adulthood is reached. The surgical procedure involve a combination of a) scapular lowering with either shift of the origin or the insertion of the scapular muscles on the spine or scapula, b) resection of superomedial border and c) omovertebral bar resection. 


\section{CONCLUSION}

An association of Sprengel's deformity with unilateral absent kidney is a rare congenital abnormality. It should not be left undiagnosed. We must diagnose this condition early in childhood and solve patient 's cosmetic and functional problem.

\section{ACKNOWLEDGEMENTS}

All authors are thankful to the concerned patient, for his written consent to publish this article.

\section{REFERENCES}

1. Grogan D P, Stanley E A and Bobechko W P. The congenital undescended scapula. Surgical correction by the Woodward procedure. J Bone Joint Surg Br 1983 ; 65 (5): 598-605.

2. Cho T J, Choi I H, Chung CY, Hwang J K. The Sprengel deformity morphometric analysis using $3 \mathrm{D}-\mathrm{CT}$ and its clinical relevance. $\mathrm{J}$ Bone Joint Surg Br. 2000 ; 82: 711-8.
3. Eulenberg M. Casuistische mittelheilungen aus dem gembeite der orthopadie. Arch Klin Chir. 1863; 4: 301-311.

4. Willet A and Walsham W J. A second case of malformation of the left shoulder-girdle ; removal of the abnormal portion of bone; with remarks on the probable nature of the deformity. Med Chir Trans 1883;66:145-158.

5. Sprengel O K. Die angeborene verschiebung des schulterblattes nach oben. Archiv Fur Klinische Chirurgie, Berlin 1891; 42: 545549.

6. Kolliker T. Mittheilungen aus der chirurgischen casuistic und kleinere mittheilungen. Bemerkungen zum aufsatze von Dr. Sprengel. Die angeborene verschiebung des schulterblattes nach oben. Arch Klin Chir 1891; 42: 925.

7. Matsuoka T, Ahlberg P E, Kessaris N, lannarelli P, Dennehy $U$, Richardson W D, et al. Neural crest origins of the neck and shoulder. Nature 2005; 436 (7049): 347-355.

8. Hamner DL and Hall JE. Sprengel's deformity associated with multidirectional shoulder instability. J Pediatr Orthop 1995;15 (5): 641-643.

9. Samartzis D, Herman J, Lubicky JP and Shen FH. Sprengel's deformity in Klippel-Feil syndrome. Spine 2007; 32 (18): E 512E516.

10. Cavendish ME. Congenital elevation of the scapula. J Bone Joint Surg Br 1972; 54 (3):395-408.

\section{Authors Contribution:}

AS - Concept, definition of intellectual content, literature search, participated in clinical data \& photograph collection, manuscript preparation; AB - Definition of intellectual content, manuscript revision; SKD - definition of intellectual content, literature search, manuscript revision; KM - literature search, clinical data \& photograph collection, manuscript preparation; SKS - literature search, clinical data collection, manuscript revision.

Source of Support: Nil, Conflict of Interest: None declared. 